\title{
PARCERIA NOS EMPRÉSTIMOS DE LIVROS ENTRE BIBLIOTECAS UNIVERSITÁRIAS
}

\author{
RICARDO CESAR SILVA* \\ GILNEI LUIZ DE MOURA** \\ EMÍDIO GRESSLER TEIXEIRA*** \\ LAÉRCIO ANDRÉ GASSEN BALSAN ${ }^{\star \star \star *}$
}

\begin{abstract}
RESUMO
Este estudo analisa a possibilidade de estabelecimento de parcerias entre instituições universitárias com o objetivo de compartilhar os acervos de suas bibliotecas reduzindo assim o custo de manutenção e proporcionando uma maior eficiência no atendimento ao usuário. Para tanto, realizou-se uma pesquisa de caráter exploratório. $\mathrm{Na}$ organização dos dados, fez-se uso da Gestão de Processos modelagem de processos por meio da Unified Modeling Language. Em linhas gerais, o estabelecimento de parcerias entre as bibliotecas mostrara-se exequível, com possibilidade de disponibilização de diversas obras, economia na replicação de acervos das instituições e criação de um modelo de empréstimo entre bibliotecas que possa ser utilizado em outras cidades.
\end{abstract}

PALAVRAS-CHAVE: Instituição de Ensino Superior. Biblioteca. Gestão de Processos. Mapeamento de processos.

\begin{abstract}
This study analyses the possibility of establishing partnerships between academic institutions with the objective of sharing the collections of their libraries, reducing the cost of maintenance and providing a greater efficiency in the service to the user. For this, an exploratory research was carried out. In the organization of the data, it was made use of Process Management - process modeling through Unified Modeling Language. In general terms, the establishment of partnerships between libraries proved to be feasible, with the possibility of making available various works, saving in the replication of institutions' collections, and creating a loan model between libraries
\end{abstract}

\footnotetext{
Universidade Federal de Santa Maria - Mestre em Gestão de Organizações Públicas.

** Universidade Federal de Santa Maria - Doutor em Administração.

*** Universidade Federal de Santa Maria - Mestre em Administração.

**** Universidade Federal de Santa Maria - Doutor em Administração.
} 
that can be used in other cities.

KEYWORDS: Institution of Higher Education. Library. Processes management. Mapping processes.

\section{INTRODUÇÃO}

As Instituições de Ensino Superior vêm enfrentando um problema relacionado à explosão informacional, a falta de espaço e aumento dos custos estruturais e de materiais, o que torna cada vez mais inviável a disponibilidade de um acervo bibliográfico que contemple em sua totalidade as necessidades da comunidade.

A prática de duplicar acervos passou a não ser a mais recomendada, e bibliotecas pertencentes a uma mesma instituição começaram a oferecer serviços em parceria (ALVAREZ, 2013). Para além, da parceria estabelecida entre bibliotecas de uma mesma instituição, outra via plausível para melhorar a situação é a parceria entre bibliotecas de instituições diferentes (BRINKERHOFF, 2002).

As Bibliotecas Universitárias estão no bojo das atividades-fim das instituições de ensino superior, citadas por Low (2004, p. 11) como de "[...] ensino-aprendizagem, compreendendo, entre outras, acesso a informação e conhecimento, espaços virtuais de aprendizagem e meios de comunicação".

Com o objetivo de implementação de serviços e produtos que visem à qualidade, a Gestão de Processos pode ser um facilitador, visto que padroniza as atividades e trabalha em consonância com os objetivos organizacionais. Além disso, aperfeiçoa as atividades e elimina os gargalos que ocasionam gastos irracionais de recursos, proporcionando um melhor manejo da força de trabalho e uma economia de tempo em relação à oferta de produtos e serviços aos cidadãos-usuários do sistema (CRUZ, 2010).

Para essa otimização, existem ferramentas que facilitam a compreensão dos processos, decomposição e interação: os Manuais Administrativos, que podem ser utilizados para descrevê-los; a Linguagem de Modelagem Unificada (Unified Modeling Language UML), que dá um panorama geral (Diagrama de Casos de Uso) e um específico (Diagrama de Atividades) dos processos; e, por fim, a Gestão do Conhecimento, que valoriza os conhecimentos tácito e explícito inerentes às pessoas, facilitando a tomada de decisão e a construção eficiente dos processos.

Dessa forma, esta pesquisa utiliza o mapeamento de processos com vistas a contribuir para que instituições universitárias 
possam se sentir motivadas a estabelecerem parcerias e, assim, além de reduzirem os custos de manutenção do acervo bibliográfico, consigam proporcionar um atendimento mais amplo aos seus usuários/clientes. Ao se considerar municípios localizados no interior, onde segundo Alvarez (2013) o acesso a diferentes títulos se torna ainda mais limitado, uma vez que estão distante das capitais e cidades medianas, onde estão concentrados os maiores centros universitários e boa parte do acervo cultural do país museus, bibliotecas, centros de documentação, as parcerias se tornam ainda mais relevantes.

Inserida nesta temática, esta pesquisa verifica a possibilidade de estabelecimento de parcerias entre instituições universitárias com o objetivo de compartilhar os acervos de suas bibliotecas, reduzindo assim o custo de manutenção e proporcionando uma maior eficiência no atendimento ao usuário. Em termos específicos, a pesquisa objetiva: a) identificar as informações úteis para a realização dos Mapeamentos de Processos dos empréstimos entre as instituições; e, b) mapear cada processo e a interação dos stakeholders envolvidos por meio de diagramas.

\section{BIBLIOTECAS UNIVERSITÁRIAS}

A biblioteca deve estar em sintonia com a universidade a qual está inserida, uma vez que esta reflete e determina a qualidade da organização (MILANESI, 1985).

As Bibliotecas Universitárias fornecem produtos e serviços informacionais, bem como salvaguardam os materiais bibliográficos e digitais das organizações para fins de pesquisa, ensino e extensão.

Para Nascimento (2009, p. 18), a Biblioteca Universitária é um:

[...] espaço informacional que, devidamente mobilizado, converter-se-á em equipamento estratégico da maior importância para o alcance das novas formas de gerenciamento das IES. A biblioteca universitária tem como papel principal subsidiar as diversas ações em que a tomada de decisão é requerida, seja na esfera acadêmica, administrativa ou cultural da instituição a que pertence. Sua missão, pois, é apoiar as atividades de ensino, pesquisa e extensão, técnico-administrativa, político-cultural e artística da Universidade. [...] deve-se implementar modelos gerenciais [...] na qualidade dos produtos oferecidos aos seus usuários.

A Biblioteca Universitária deve gerir a Informação, que, consoante Dias e Belluzzo (2003), consiste em um conjunto de conceitos, princípios, métodos e técnicas, os quais são utilizados na 
prática administrativa que visa o serviço de informação para atingir a missão e os objetivos desejados. De acordo com Choo (2003), pode ser compreendida como a gestão de uma rede de processos: adquire, cria, organiza, distribui e usa a informação.

Além da disseminação de informação e conhecimento, as Bibliotecas Universitárias oferecem uma gama de serviços que podem ser mapeados e melhor readequados à realidade de cada instituição. Elas podem, também, trabalhar em conjunto com outras instituições no intuito de oferecer uma vasta coleção bibliográfica e digital aos seus usuários/clientes.

As Bibliotecas Universitárias possuem, no seu modus operandi, produtos e serviços de origem complexa (processos) que são aperfeiçoados dia a dia. Hammer (2013, p. 11) afirma que "[...] os conceitos de processo e a gestão de processos não se aplicam apenas a estrutura do e transacional [...] também podem ser associados aos processos de desenvolvimento que estão centrados em atividades altamente criativas [...]" e define que "todo o trabalho é processual" (HAMMER, 2013, p. 11).

Dessa maneira, se todo o trabalho é processual, deve ser otimizado para eliminar os gargalos que dificultam o gasto racional das receitas públicas e privadas, proporcionando um melhor manejo da força de trabalho e uma economicidade de tempo em relação à oferta de produtos e serviços aos cidadãos usuários do sistema.

\section{GESTÃO E MAPEAMENTO DE PROCESSOS}

A Gestão de Processos, no sentido estritamente empresarial, caracteriza-se como os incrementos e as transformações que os produtos e serviços passam desde a sua entrada "inputs" até a sua saída "outputs" da empresa. Os processos, de acordo com Davenport (1994), constituem uma sincronização de atividades de trabalho com tempo - começo, meio e fim - e espaço definidos.

Segundo Campos (2009), processos são atividades repetitivas logicamente organizadas que visam obter resultados em consonância com a missão institucional. A Gestão de Processos obstina-se à redução do retrabalho, à economia de recursos materiais e humanos, à eficiência do trabalho e à busca pela qualidade de produtos e serviços. Para Davenport (1994, p. 8), processos são "[...] a estrutura pela qual uma organização faz o necessário para produzir valor para os seus clientes".

Os processos, conforme Araújo e Alvarez (2009), são 
formados por cinco elementos: insumos (inputs) - fatores que iniciam a produção ou serviço (matérias-primas, dados iniciais que gerarão relatórios etc.); recursos responsáveis pelo suporte à produção (capital, mão de obra); atividades - há duas ramificações: a identificação (delimita a atividade) e os procedimentos (explicam como será feita a atividade); e informação e tempo - elementos que perpassam os processos em todas as suas etapas, ou melhor, estão embutidos nas fases desde os inputs até os outputs, e indicam o como fazer e o tempo que demorará até o seu término.

Para se atingir os processos falhos dentro das empresas, é necessário conhecê-los por meio das técnicas de Mapeamento de Processos, que consistem em utilizar uma metodologia conhecida, padronizada, de fácil utilização, com documentação e linguagem claras e objetivas, para subsidiar a tomada de decisão.

Em vista disso, existem várias ferramentas para o Mapeamento de Processos. Uma delas é a metodologia UML, uma linguagem visual voltada para orientação a objetos. O método UML surgiu da união de três outros métodos que eram utilizados em 1990: Booch, OMT e OOSE. Em meados de 1996, emanou a primeira versão UML com aceitação dos programadores, pois se tratava de uma padronização dos três maiores métodos aceitos no mercado de desenvolvimento de softwares (GUEDES, 2011).

O sistema de modelagem UML trabalha com diagramas, a fim de que se tenha a visão de todos os processos e, também, de suas especificidades. São eles: o diagrama de Casos de Uso e o diagrama de Atividades.

O diagrama de Casos de Uso dá uma visão geral das pessoas envolvidas nos processos e de quais atividades terão que desempenhar. Na visão de Guedes (2011, p. 30),

O diagrama de Casos de Uso é o diagrama mais geral e informal da UML, utilizado normalmente nas fases de levantamento e análise de requisitos do sistema, embora venha a ser consultado durante todo o processo de modelagem e possa servir de base para outros diagramas. Apresenta uma linguagem simples e de fácil compreensão para que os usuários possam ter uma ideia geral de como o sistema irá se comportar. Procura identificar os atores (usuários, outros sistemas ou até mesmo algum hardware especial).

O modelo de análise UML do diagrama de Casos de Uso (visão global dos processos) apresenta os atores envolvidos, a interação dos atores em relação a outros atores e os atores e 
seus processos. Apresenta, também, as relações include verificação de outro processo para determinar a sua execução e extend - verificação de processo acessório, que pode ou não ser acionado às suas condições para a consecução final. A diferença do include para o extend refere-se que o primeiro é uma condição sine qua non para a finalização da atividade.

Todavia, quando se necessita olhar a peculiaridade de um processo, quais são as suas atividades de início, meio e fim, é necessário utilizar o diagrama de Atividades, o qual, de acordo com Guedes (2011, p. 36) "[...] preocupa-se em descrever os passos a serem percorridos para a conclusão de uma atividade específica, podendo esta, ser representada por um método com certo grau de complexidade, um algoritmo, ou mesmo por um processo completo". Ainda conforme o autor, "[...] concentra-se na representação do fluxo de controle de uma atividade".

No diagrama de Atividades, existem vários tipos de elementos para identificar a sequência do processo: início e fim, decisão (condição), esclarecimento da decisão, junção e divisão de atividades.

A metodologia UML foi escolhida por ser padronizada, de ampla aceitação, com linguagem fácil e acessível, uma vez que existem softwares gratuitos para a modelagem de sistemas, como o Astah. Os diagramas de Casos de Uso e de Atividades foram adotados em função de abarcarem a visão geral (Casos de Uso) e específica (Atividades). Podem ser aplicados e adaptados em diversos ramos de atuação, haja vista que podem elencar atividades e processos e não entrar nos pormenores das linguagens de programação.

\section{METODOLOGIA}

Esta pesquisa exploratória foi realizada em quatro universidades localizadas em um município do interior do Estado do Rio Grande do Sul. Dessas, três são públicas e uma privada. As universidades escolhidas estão próximas uma em relação às outras em aproximadamente $10 \mathrm{~km}$, o que facilita a locomoção da comunidade entre os campi para obtenção dos empréstimos.

A pesquisa Exploratória, segundo Gil (2010), caracteriza-se por proporcionar familiaridade com o problema, construção e elucidação de hipóteses, e tem como peculiaridade 0 planejamento flexível, pois conecta os mais variados aspectos, 
fatos ou fenômenos relacionados à pesquisa.

O primeiro passo realizado durante a coleta de dados foi o levantamento de informações junto às instituições, por meio da observação não participante. Nesse momento, foi possível verificar como eram realizados os empréstimos domiciliares, quais eram os prazos de devolução e, no caso de atraso, como ocorria o pagamento da multa. A duração da observação não participante deu-se em torno de dois dias em cada instituição. $O$ estudo limitou-se a observar o cotidiano das bibliotecas sem intromissão da opinião do pesquisador a respeito de quaisquer ações de melhorias. Os dias em que o pesquisador se dirigiu às instituições foram previamente agendados, com uma semana de antecedência, junto às direções das bibliotecas investigadas.

Em seguida, foi aplicado um questionário semiestruturado a quatro bibliotecários das bibliotecas pesquisadas para levantamento de alguns dados: se era favorável à implantação da parceria; como deveria ser realizado o processo de empréstimo entre as instituições; quais garantias as organizações deveriam prestar uma em relação à outra - caso ocorra um extravio do material; e, se haveria alguma restrição de quantidade ou material a ser disponibilizado. Todos os dados coletados foram manualmente transcritos e, depois, organizados digitalmente.

A análise dos dados referentes aos questionários foi realizada por meio da análise de conteúdo das mensagens, buscando descobrir que sentidos o emissor pretendeu transmitir.

O terceiro passo consistiu em mapear e criar todos os processos, de acordo com as informações levantadas, de interação dos stakeholders (alunos, funcionários e instituição) para a realização dos empréstimos entre as bibliotecas das instituições. Esse mapeamento foi realizado por meio do método UML (Unified Modeling Language).

\section{APRESENTAÇÃO DOS DADOS}

Ao serem questionados, os bibliotecários participantes da pesquisa, demonstraram concordar com a possibilidade do estabelecimento de uma parceria entre as bibliotecas das IES com o objetivo de compartilhar seus acervos.

Também sugeriram a elaboração de um projeto para que o mesmo fosse entregue aos dirigentes das universidades. Tal fato pode ser observado no relato da pessoa intitulada como " $A$ ": 
A possibilidade de união entre as instituições [...] preocupadas com a disseminação informacional converte-se na esperança de que é possível realizarmos procedimentos que atendam à comunidade de forma integrada e coesa mediante apoio das equipes diretivas institucionais. Devemos pensar em projetos que viabilizem a exploração de sistemas e serviços integrados, observando se os mesmos também viabilizam e não dificultam o processo de gerenciamento nas unidades informacionais em que os bibliotecários trabalham.

Ressalta-se, a preocupação com o apoio dos dirigentes das instituições: "A princípio, teria que conversar com a equipe diretiva da instituição, pois todas as metodologias de trabalho implementadas, no setor, passam por suas análises" (Bibliotecário A).

Em relação à integração dos sistemas entre as instituições e de como isso poderiam ser feito, os bibliotecários informaram que já trabalharam com empréstimos entre bibliotecas de uma mesma instituição. No entanto, nunca trabalharam com empréstimos entre bibliotecas de instituições diferentes. A descrição do respondente "A" evidencia isso: "Já trabalhei com empréstimos realizados entre bibliotecas, mas da mesma instituição. Não possuo experiência com sistemas distintos, não saberia informar como funcionaria a integração do catálogo das mesmas".

Ressaltaram, também, as dificuldades que poderiam surgir com relação à integração de sistemas: "as universidades prezam pelo sigilo das informações dos seus usuários e os sistemas de bibliotecas são, muitas vezes, distintos em relação às linguagens de programação e empresas fornecedoras" (Bibliotecário B).

No que compete à pergunta relacionada à validação do usuário e responsabilização da instituição ao qual o usuário está vinculado, os colaboradores indicaram que esta deve partir da instituição de origem, conforme descrito pelo bibliotecário "B": "Acredito que o empréstimo deva ser realizado à instituição solicitante, essa deve se responsabilizar em como será efetuada, em sua unidade, o empréstimo para o usuário". E ressaltaram que a validação do usuário é uma condição sine qua non para o sucesso da parceria, consoante o bibliotecário "B" continua: "Teria que ver uma forma na qual fosse possível saber se o aluno está matriculado na outra instituição, ou seja, se é um aluno regular. Visto que é o norte principal para uma propositura de 
parceria entre as instituições".

Três outras preocupações foram levantadas pelos profissionais envolvidos na pesquisa: a padronização de processos, a participação coletiva nas decisões e o transporte dos materiais bibliográficos. O bibliotecário "C" afirma: "Penso que deveríamos criar um modelo padronizado para as bibliotecas parceiras, para que todas possam prosseguir da mesma maneira em relação ao empréstimo. Isso precisaria ser discutido e analisado por todos os envolvidos".

Quanto ao transporte dos materiais bibliográficos, o bibliotecário "C" sugeriu que as instituições se organizem para "Implantar um sistema entre as bibliotecas de uma entrega via malote".

No que se refere a possíveis restrições relacionadas à quantidade de materiais a serem emprestados, os profissionais mencionaram a necessidade de estipular um limite. Conforme o excerto mencionado pelo bibliotecário "A": "Acredito que deve haver um limite de livros a ser retirado por alunos para que não prejudique os estudantes da Instituição, isso deve ser estudado e estabelecido em conjunto".

Quando foram questionados sobre a importância de haver alguma forma de garantia entre as instituições, caso ocorra extravio de algum material pela comunidade acadêmica, os colaboradores consideraram isto como de suma relevância. O bibliotecário " $D$ " indicou o seguinte:

Seria muito importante a elaboração de um documento que descreva que a instituição também se responsabiliza pelas perdas e extravios de materiais oriundos de empréstimos para sua unidade. Seria de responsabilidade da instituição solicitante do material que reponha a obra extraviada, assim como, no caso de título esgotado que entre em contato com a instituição que lhe realizou o empréstimo para acordarem qual título o substituirá.

A partir das respostas dos bibliotecários e da observação não participante, foram construídos diagramas de atividades, cuja metodologia utilizada para designar os passos do fluxo principal e alternativos do diagrama de Casos de Uso foi extraída de Wazlawick (2011).

A representação pictórica da especificação do Caso de Uso pode ser observada na Figura 1. 
FIGURA 1 - Diagrama empréstimo entre bibliotecas.

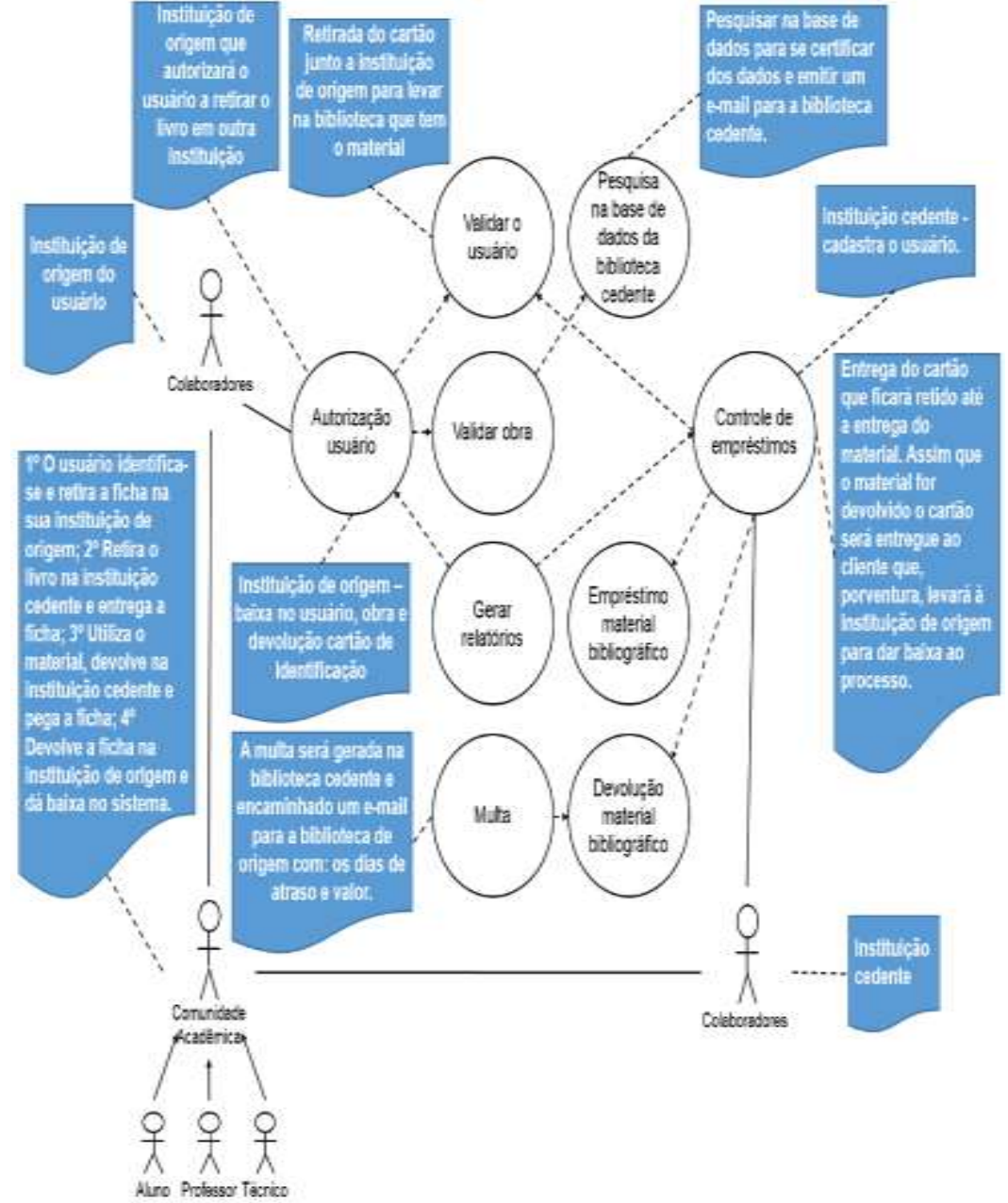

FONTE: elaborado pelo autor.

$\mathrm{Na}$ sequencia é apresentado um passo a passo de como deverão ser realizadas as atividades e processos entre as bibliotecas no caso de parcerias entre as instituições.

O primeiro passo é estabelecer uma relação de parceria entre as instituições, por meio de um acordo firmado, via contrato, e de um 
aceite para ressarcimento caso algum usuário danifique, extravie ou não proceda à devolução do material.

Na Figura 2, observa-se a relação entre as universidades para o ressarcimento quando houver perda de material ou dano.

FIGURA 2 - Diagrama Atividade: Ressarcimento entre as instituições.

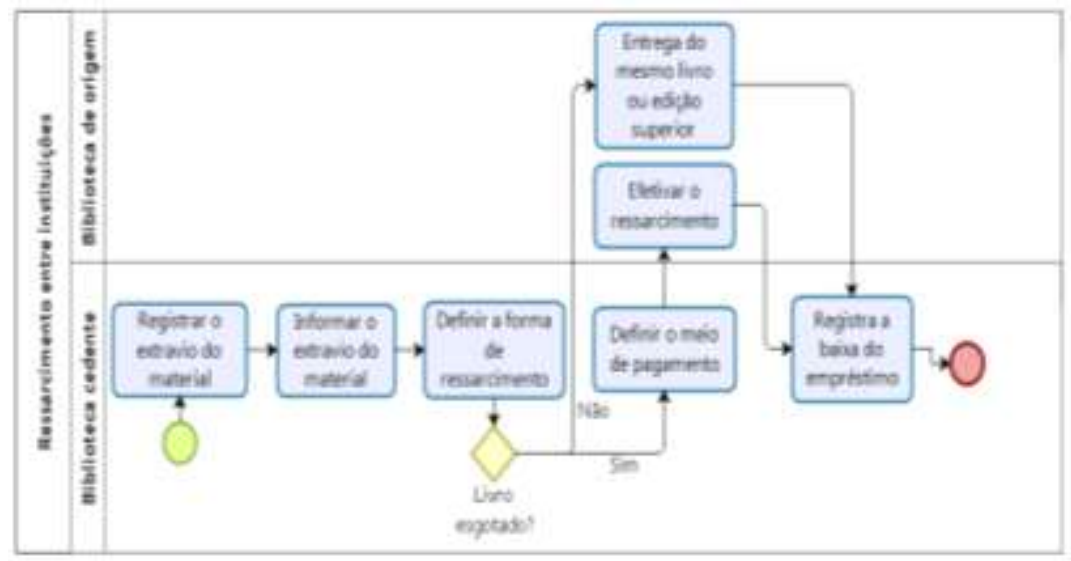

FONTE: Elaborado pelo autor.

Essa atividade só será utilizada, caso o usuário, por algum motivo, não devolva o livro e não ressarça a instituição cedente. Dessa forma, ficará com pendência na instituição de origem, pois esta entrará em contato com a instituição cedente e devolverá o livro de mesma edição ou superior e, caso o livro esteja esgotado, pagará o valor do livro em espécie.

$\mathrm{Na}$ Figura 3 , observa-se o passo a passo referente às atividades e processos que cada ator deve trilhar para a consecução do serviço de empréstimo entre as bibliotecas. São descritas as etapas do processo de reserva do material em relação à biblioteca que dispõe do acervo. 
FIGURA 3 - Solicitação de reserva do material.

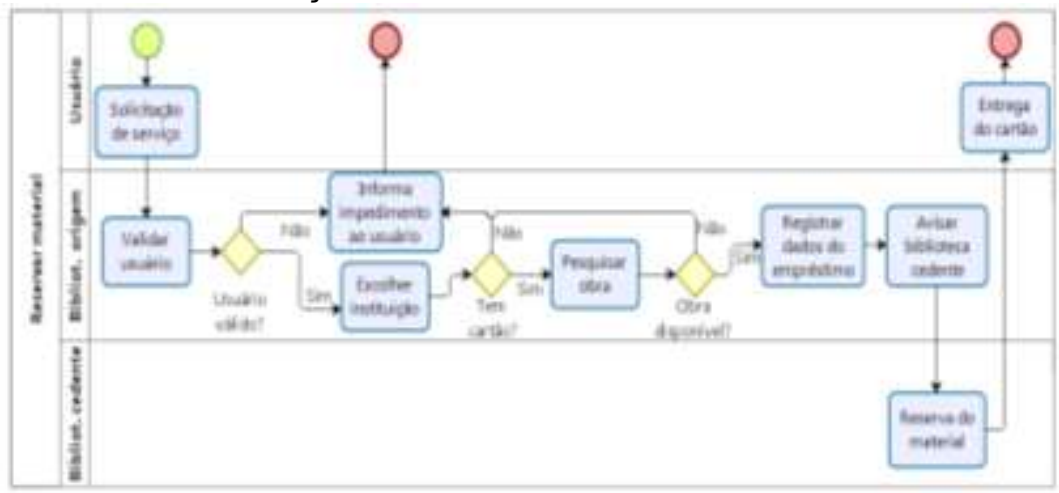

FONTE: Elaborado pelo autor.

Na Figura 4, menciona-se o trâmite para a retirada do material na biblioteca da instituição cedente.

FIGURA 4 - Retirada do material na biblioteca da instituição cedente.

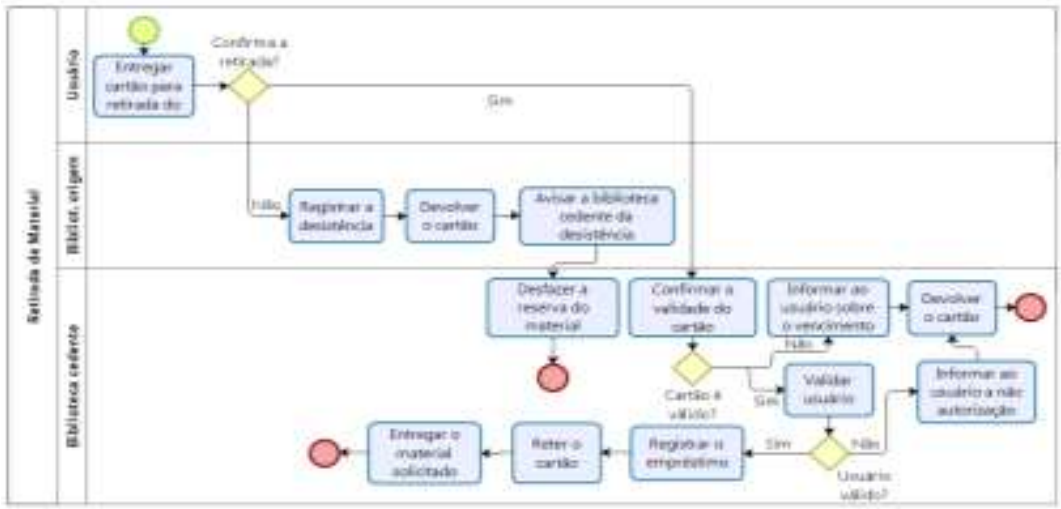

FONTE: Elaborado pelo autor.

A Figura 5 apresenta as etapas a serem cumpridas pelo usuário para efetuar a devolução do material emprestado pela 
biblioteca cedente e explica como se dará a cobrança de multa em caso de atraso ou extravio do material.

FIGURA 5 - Devolução do material à instituição da biblioteca cedente.

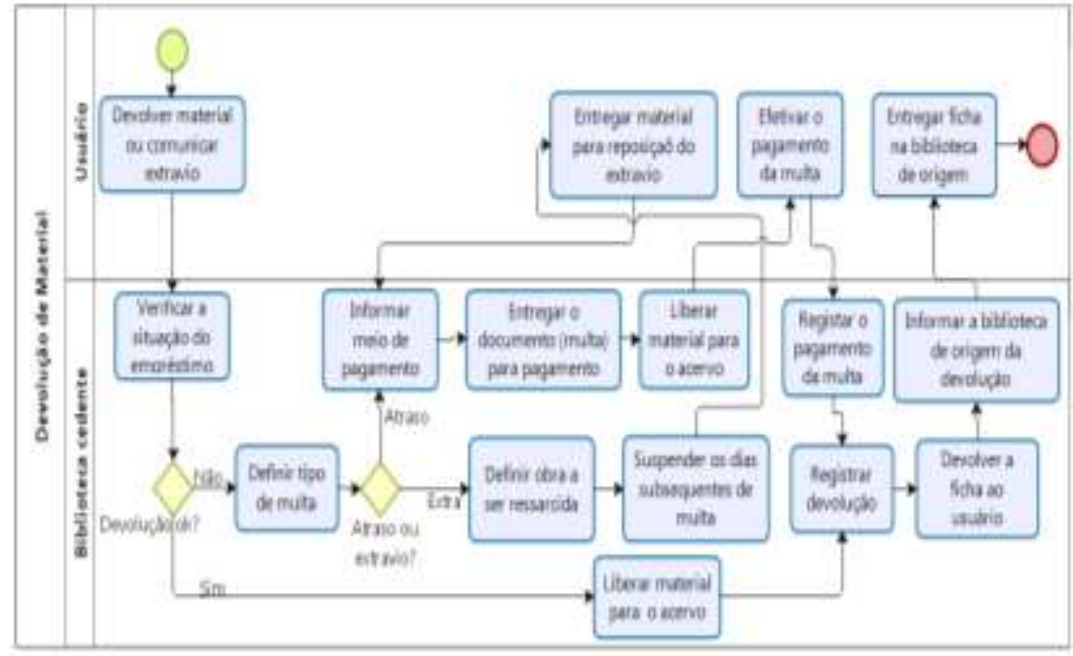

FONTE: Elaborado pelo autor.

\section{CONSIDERAÇÕES FINAIS}

As organizações, sejam elas públicas ou privadas, almejam, em um primeiro momento, atender às necessidades de seus clientes/usuários e, por conseguinte, criar uma esfera positiva de confiança e superação em relação à qualidade de seus produtos e serviços. Uma das formas de agregar valor ao seu produto/serviço pode ocorrer por meio das parcerias.

As bibliotecas representam um elevado custo para seus mantenedores. Nesse sentido, as parcerias entre instituições universitárias podem favorecer uma redução de custos e uma maior efetividade dos serviços prestados. No decorrer da pesquisa, notou-se que a parceria entre instituições universitárias é possível por meio de processos mutuamente acordados e chancelados. Somado a isso, há uma visão de receptividade por parte dos bibliotecários facilitando o processo. Tal fato poderia ser um impedimento, visto que mudar a cultura e a percepção dos bibliotecários poderia ser algo demorado e custoso. 
Ressalta-se que os processos aqui mapeados podem ser replicados para a integração de instituições localizadas em outras cidades. Para tanto, alguns aspectos devem receber atenção especial: comprometimento dos dirigentes das IES, integração dos sistemas de empréstimo, fluxo de informações, padronização dos processos, ressarcimento de materiais perdidos ou não devolvidos entre as instituições, catálogo único e disponibilização de dados para pesquisa acerca dos dados dos usuários de outras instituições. Este último fator, pode gerar um desconforto entre as instituições, uma vez que os dados são sigilosos, no sentido de que a responsabilização e a validação do usuário partem da instituição de origem, e a cedente só realiza o empréstimo.

Os bibliotecários responsáveis pelas bibliotecas da rede mencionaram duas condições sine qua non para o sucesso de qualquer parceria entre as bibliotecas, referentes a seus acervos bibliográficos: a realização de empréstimo domiciliar e o catálogo online. O primeiro, em virtude dos empréstimos para os usuários, pois, se a instituição priorizar a pesquisa somente nas suas dependências, sem a realização de saída do material bibliográfico, a parceria se tornará inviável em virtude de descaracterizar o sistema bilateral. Por conseguinte, o catálogo online é imprescindível em virtude de as outras instituições validarem se o material existe nas bibliotecas da rede e se está disponível para o empréstimo.

Como limitações do estudo citam-se as próprias do estudo exploratório e o desenvolvimento realizado em apenas uma cidade. Por isso, propõem-se a replicação da pesquisa em outras realidades, a extensão de sua abrangência para outras instituições, bem como a verificação da possibilidade e a melhor forma para o estabelecimento de parcerias entre bibliotecas localizadas em diferentes municípios.

Esta investigação limitou-se aos materiais bibliográficos, e, como proposta de trabalhos futuros, ficam os meios digitais - as bases de dados. Acordos de parceria entre as instituições com os distribuidores dessas bases podem gerar bons frutos: redução de custos operacionais e oferta de mais informações e conhecimentos aos players envolvidos, assim como ocorre em larga escala no Brasil com o Portal de Periódicos da Capes.

\section{REFERÊNCIAS}

ALVAREZ, A. M. T. Panorama e diagnóstico da oferta e qualidade da
educação $\begin{aligned} & \text { superior brasileira. } 2013 . \\ & \text { Disponível em: }\end{aligned}$ 
$<$ http://portal.mec.gov.br/index.php?

option=com_docman\&task=doc_download\&gid=13944\&ltemid;=.>. Acesso em: 15 abr. 2015.

ARAÚJO, J. F.; ÁLVAREZ, E. J. V. La modernización administrativa y la gobernanza em los concellos del Eixo Atlântico do Noroeste Peninsular. Vigo: Eixo Atlântico do Noroeste Peninsular, 2009.

BRINKERHOFF, J. M. Government-Nonprofit Partnership: a defining framework. Public Administration and Development, v. 22, n. 1, p.19-30, 2002.

CAMPOS, J. P. Mapeamento de processos: uma estratégia vencedora. 2009. Disponível em: <http://www.aprendersempre.org.br/arqs/GE B Mapeamento de processos- uma estratégia vencedora.pdf $>$. Acesso em: 15 abr. 2015.

CHOO, C. W. A organização do conhecimento: como as organizações usam a informação para criar significado, construir conhecimento e tomar decisões. São Paulo: Senac, 2003.

CRUZ, T. Sistemas, organizações e métodos: estudo integrado das novas tecnologias da informação e introdução à gerência do conteúdo e do conhecimento. São Paulo: Atlas, 2010.

DAVENPORT, T. Reegenharia de processos: como inovar na empresa através da tecnologia da informação. Rio de Janeiro: Campus, 1994.

DIAS, M. M. K.; BELLUZZO, R. C. B. Gestão da informação em ciência e tecnologia sob a ótica do cliente. São Paulo: EDUSC, 2003.

GIL, A. C. Como elaborar projetos de pesquisa. São Paulo: Atlas, 2010.

GUEDES, G. T. A. UML 2: uma abordagem prática. São Paulo: Novatec, 2011.

HAMMER, M. O que é Gestão de Processos de Negócio? In: BROCKE, J. V.; ROSEMANN, M. Manual de BPM: Gestão de processos de negócio. Porto Alegre: Bookman, 2013, p. 3-16.

LOW, T. A percepção sobre o valor da utilização de recursos de ti para a atividade-fim em uma instituição de ensino superior. 2004. $150 \mathrm{f}$. Dissertação (Mestrado em Administração) - Universidade Federal do Rio Grande do Sul, Porto Alegre, 2004.

MILANESI, L. O que é biblioteca. São Paulo: Brasiliense, 1985.

NASCIMENTO, E. G. V. Método de gestão para biblioteca universitária baseado no balanced scorecard. 2009. 105 f. Dissertação (Mestrado em Políticas Públicas e Gestão da Educação Superior) - Universidade Federal do Ceará, Fortaleza, 2009.

WAZLAWICK, R. S. Análise e projeto de sistemas de informação orientados a objetos. Rio de Janeiro: Elsevier, 2011. 